\title{
Economia circular e passivo ambiental da indústria têxtil: análise de empresas do setor da moda brasileiro
}

O presente artigo investigou a Economia Circular (EC) e o passivo ambiental da indústria têxtil, na tentativa de responder o seguinte questionamento: Considerando o elevado impacto ambiental da indústria têxtil, de que maneira a adoção da EC pode ser transformada em alternativa para o lançamento estrutural do passivo ambiental de empresas do setor da moda em seus relatórios financeiros? Pretendeu-se, especificamente: (i) descrever os formatos de EC adotadas por empresas do setor da moda, (ii) identificar lançamentos estruturais de iniciativas socioambientais e (iii) identificar lançamentos estruturais do passivo ambiental. Este trabalho se justifica por discutir a problemática dos resíduos têxteis e as possibilidades alinhadas às dimensões da sustentabilidade no âmbito da indústria têxtil. A revisão teórica engloba discussões sobre sustentabilidade, economia circular e passivo ambiental. A coleta de dados se deu pela análise qualitativa de relatórios de três grandes empresas do setor da moda que já possuíam iniciativas de EC. Nos resultados, constatou-se que as empresas pesquisadas podem utilizar, de forma mais efetiva, as informações relacionadas aos gastos com iniciativas socioambientais e, também, incluir as informações acerca do passivo ambiental por meio do seu lançamento estrutural em relatórios financeiros. A EC, bem como a implementação de iniciativas socioambientais ao serem adotadas pelas empresas podem integrar as informações financeiras das organizações de forma a contrapor possíveis passivos ambientais e, assim, possibilitar a avaliação do nível do compromisso organizacional no que diz respeito à atuação em formato positivo para sociedade e limpo para o meio ambiente.

Palavras-chave: Economia Circular; Sustentabilidade; Indústria Têxtil; Passivo Ambiental.

\section{Circular economy and environmental liability of the textile industry: analysis of companies in the Brazilian fashion sector}

\begin{abstract}
This article investigated the Circular Economy $(\mathrm{EC})$ and the environmental liabilities of the textile industry, in an attempt to answer the following question: Considering the high environmental impact of the textile industry, how can the adoption of EC be transformed into an alternative for the launch structural impact of environmental liabilities of fashion companies in their financial reports? The intention was specifically to: (i) describe the EC formats adopted by the fashion companies, (ii) identify structural launches of socio-environmental initiatives and (iii) identify structural launches of the environmental liability. This work is justified for discussing the problem of textile waste and the possibilities aligned with the dimensions of sustainability in the context of the textile industry. The theoretical review includes discussions on sustainability, circular economy and environmental liabilities. Data collection was done through the qualitative analysis of reports from three large fashion companies that already had EC initiatives. In the results, it was found that the companies surveyed can effective use information related to spending on social and environmental initiatives and also include structural information about environmental liabilities through the entry of this information in financial reports. EC, as well as the implementation of socio-environmental initiatives when adopted by companies, can compose the financial information of organizations in order to counter possible environmental liabilities and, thus, enable the assessment of the level of organizational commitment with regard to acting in a positive format for society and clean for the environment.
\end{abstract}

Keywords: Circular Economy; Sustainability; Textile Industry; Environmental liability.

Topic: Gestão Ambiental e da Biodiversidade

Reviewed anonymously in the process of blind peer.

Fernanda Costa Silva (io

Centro Federal de Educação Tecnológica de Minas Gerais, Brasil http://lattes.cnpq.br/0133074650808894

http://orcid.org/0000-0002-7731-1603

fernanda.corrs@gmail.com

Bárbara Gabrielle Silva (ib)

Centro Federal de Educação Tecnológica de Minas Gerais, Brasil http://lattes.cnpq.br/6525272066238635 http://orcid.org/0000-0002-4086-014X

barbarags96@hotmail.com

Ana Luiza Monteiro Bastos Ornellas

Centro Federal de Educação Tecnológica de Minas Gerais, Brasil http://lattes.cnpq.br/4096831893245408

http://orcid.org/0000-0001-8052-2957

ana luizamonteiro@hotmail.com

DOI: 10.6008/CBPC2179-684X.2020.004.0020
Received: 10/10/2020

Approved: 21/12/2020

\author{
Fabrício Molica de Mendonça (iD \\ Centro Federal de Educação Tecnológica de Minas Gerais, Brasil \\ http://lattes.cnpq.br/9496154537888733 \\ http://orcid.org/0000-0001-8909-6843 \\ fabriciomolica@yahoo.com.br \\ Lívia Maria de Pádua Ribeiro (iD \\ Centro Federal de Educação Tecnológica de Minas Gerais, Brasil \\ http://lattes.cnpq.br/3836203930867479 \\ http://orcid.org/0000-0002-5271-9397 \\ livia.padua2014@gmail.com
}

Referencing this:

SILVA, F. C.; SILVA, B. G.; ORNELLAS, A. L. M. B.; MENDONÇA, F. M.; RIBEIRO, L. M. P.. Economia circular e passivo ambiental da indústria têxtil: análise de empresas do setor da moda brasileiro. Revista Brasileira de Administração Científica, v.11, n.4, p.259-275, 2020. DOI: http://doi.org/10.6008/CBPC2179-684X.2020.004.0020 


\section{INTRODUÇÃO}

Os impactos ambientais ocasionados pelas organizações na produção de bens em larga escala constituem um dos grandes desafios da atualidade. $O$ consumismo originado pela racionalidade instrumental (WEBER, 1982), e frequentemente legitimado pela sociedade, ocasionou a crescente demanda por recursos naturais (PINTO et al., 2015). No mundo da moda, o cenário não foi diferente, sendo que a produção em larga escala de produtos do vestuário não coaduna apenas com a questão da roupa, mas também com a sociedade consumista a que ela se destina (LIPOVETSKY, 2009). Com esse panorama, a escalabilidade das produções e do consumo, passou a refletir desigualdades nos âmbitos social, econômico e, principalmente, ambiental.

Tal modelo, baseado em uma premissa capitalista, não contribui para a sustentabilidade do crescimento, fomenta a pobreza e degrada o meio ambiente (LUCIETTI et al., 2018). Deste modo, surgiu a necessidade de caminhar na direção de uma reabilitação da esfera social por meio de regras e normas (HABERMAS, 1989). Assim, a responsabilidade passou a ser pontuada como uma prática para o coletivo. Responsabilizar-se pelas questões ambientais e pela destinação dos resíduos das produções de bens tornouse um caminho importante a ser trilhado pelas políticas públicas e pela gestão organizacional.

A partir de então se apresentou como pauta de discussão a implementação de ações com vistas à inserção de normas e legislações que permitissem o monitoramento das organizações quanto aos impactos causados no ambiente. No cenário brasileiro, com a sanção da Lei № 10.650, de 16 de abril de 2003, grande parte das organizações passaram a proceder a divulgação dos potenciais e efetivos impactos ambientais de suas atividades, bem como seu passivo ambiental - conjunto das obrigações contraídas pelas organizações quanto às ações de controle, preservação e recuperação do meio ambiente (SANTOS et al., 2001). No ano de 2010, o governo promulgou a Lei no 12.305, de 2 de agosto de 2010 que institui a Política Nacional de Resíduos Sólidos - PNRS.

$\mathrm{Na}$ indústria têxtil, especificamente, toda a cadeia de produção gera elevado impacto ao meio ambiente (BERLIM, 2014). No entanto, as pressões advindas de regulamentações, novas tecnologias e alterações do próprio mercado tem proporcionado importante influência na implementação de ações e estratégias que visem o alinhamento da conduta dos gestores desse setor (CASTRO JÚNIOR et al., 2000). Assim, apresentando-se como uma alternativa para o cumprimento das regulamentações, bem como para a criação de valor e engajamento socioambiental, tem-se a Economia Circular (EC), opção que contribui para o gerenciamento coordenado da cadeia produtiva têxtil e redução do consumo de água e energia, ou seja, uma estratégia mais limpa e ecoeficiente (MORO et al., 2018).

Na proposição da EC, as empresas devem repensar sobre as suas cadeias de suprimentos e de interesses (LUDEKE-FREUND et al., 2018) e, de acordo com a instituição Ellen Macarthur Foundation, é considerada uma alternativa ao padrão econômico vigente de "extrair, transformar, descartar" e cuja proposta visa "redefinir a noção de crescimento, com foco em benefícios para toda a sociedade". Sendo um dos princípios da EC, manter produtos materiais em ciclos de uso conforme conceito do Cradle to Cradle (Do 
berço ao berço), idealizado por Pearce et al. (1990), a EC criativa por meio do Upcycling apresentou-se na presente pesquisa como o modelo que contempla toda a perspectiva dos seus idealizadores. O Upcycling é o processo de criar algo novo a partir de itens antigos. Ou seja, usa materiais existentes, que iriam ser descartados, mas são transformados em matérias prima para a formatação de novos produtos de qualidade semelhante ou superior a esses materiais (SHOUP, 2008). Como há muitos resíduos que podem ser reaproveitados, a técnica já é bem reconhecida e implementada na Europa (SOUZA et al., 2015) e vem ganhando relevância e a aderência de empresas brasileiras (MOREIRA et al., 2018).

Com essas constatações, intencionou-se a responder o seguinte questionamento: Considerando o elevado impacto ambiental da indústria têxtil, de que maneira a adoção da EC pode ser transformada em alternativa para o lançamento estrutural do passivo ambiental de empresas do setor da moda em seus relatórios financeiros? Pretendeu-se, especificamente: (i) descrever os tipos de EC adotadas por empresas do setor da moda, (ii) identificar lançamentos estruturais de iniciativas socioambientais e (iii) identificar lançamentos estruturais do passivo ambiental. Este trabalho se justifica por se tratar de uma tentativa de preencher a "lacuna de pesquisas que tratem especificamente do problema dos resíduos têxteis limpos na indústria e das dimensões da sustentabilidade" e nas possibilidades para a transformação econômica do modelo linear para o modelo circular (CEGLIA, 2020).

Trata-se de uma pesquisa qualitativa descritiva e de caráter exploratório, desenvolvida por meio de análise documental de Relatórios (Demonstrações Financeiras, Relatórios Anuais e Relatórios de Sustentabilidade) e materiais institucionais de três empresas do setor da moda brasileiro. $\mathrm{O}$ artigo foi dividido em revisão teórica, metodologia, resultados, discussão e considerações finais.

\section{REVISÃO TEÓRICA}

Engloba o escopo desta revisão teórica o conceito e as discussões sobre Sustentabilidade, Economia Circular (EC) e passivo ambiental da indústria têxtil.

\section{Sustentabilidade e Economia Circular (EC)}

A racionalidade instrumental retratada por Weber (1982) firmou-se em uma lógica racional ordenada e o seu desenvolvimento com base no lucro acumulativo (SANTOS et al., 2001). O termo, explicado por Tenório (1990), pode ser designada como a instrumentalização da ação social nas organizações, cujas práticas passaram a ser justificadas no âmbito dos sistemas sociais. A consequência dessa lógica na modernidade foi a constituição de uma sociedade consumista e a sobrecarga das demandas por recursos naturais (PINTO et al., 2015).

A partir dos apontamentos iniciais a respeito das projeções ambientais realizadas pelo Massachusetts Institute of Technology (MIT) na década de 1960, desdobrou-se a discussão com vistas a garantir a sobrevivência das gerações futuras. Tais apontamentos foram agrupados em um relatório denominado Limites do Crescimento (The Limits to Growth), um trabalho liderado por Meadows et al. (1972), encomendado pelo Clube de Roma. Neste relatório, foram apontadas estimativas bem realistas sobre o 
futuro do planeta em relação ao crescimento populacional, a exaustão dos recursos naturais e a necessidade de procurar tendências sustentáveis para reverter tal quadro (OLIVEIRA, 2002).

No ano de 1972, com a realização da Conferência de Estocolmo, elevou-se o patamar das discussões sobre questões ambientais (LAGO, 2007). A Organização das Nações Unidas (ONU), no ano de 1983, constituiu a Comissão Mundial sobre o Meio Ambiente e Desenvolvimento, intitulada Comissão Brundtland, cuja coordenação foi assumida por Gro Harlem Brundtland, primeira ministra da Noruega na época. No Relatório Brundtland, pioneiro na introdução do termo "desenvolvimento sustentável", definiu-se o caminho a ser trilhado com vistas a propiciar reflexão acerca do desenvolvimento da sociedade sem o comprometimento das gerações futuras.

Neste estudo, buscou-se compreender o processo de desenvolvimento sustentável como base de atuações organizacionais acopladas a capacidades técnicas, financeiras, gerenciais e estratégicas com vistas ao alcance da sustentabilidade. Conceitualmente, o termo "abrange a preocupação da sociedade com a oferta futura de bens e serviços indispensáveis à sobrevivência da humanidade" (OLIVEIRA, 2002).

Com o decorrer das discussões, o conceito "Sustentabilidade" evoluiu, sendo introduzida a ele uma abordagem sistêmica desenvolvida por John Elkington, com o termo "Triple Bottom Line" e a partir de então abrigando as dimensões econômica, social e ambiental. O sucesso organizacional passou, então, a englobar tais conjuntos de valores na política das organizações por meio de seus relatórios (FRY et al., 2008). Neste sentido, grande parte dos estudos que envolvem o termo "Sustentabilidade" principiou no reconhecimento dessas três dimensões que se relacionam econômica, ambiental e socialmente (CLARO et al., 2008).

Assim, tornou-se crescente o engajamento de instituições e da sociedade nas questões ambientais do planeta com o surgimento de movimentos com vistas a reverter e/ou minimizar os impactos ocasionados pela produção em larga escala. Nas organizações, ora para realizarem adequações legais, ora para manterem uma imagem positiva em relação às suas atividades, apontam iniciativas de gestão dos seus resíduos sólidos, buscando minimizarem seus impactos ambientais.

A gestão ambiental moderna, assentida pelas organizações com vistas a adaptação dos preceitos do triple bottom line, além de fornecer avanços mercantis no que diz respeito aos aspectos de competitividade e resultados, é entendida por Abreu et al. (2013) como "pró-atividade ambiental". Assim, o caminho a ser percorrido pelas organizações na busca pelo alinhamento da sua conduta à sustentabilidade ambiental e visando uma produção ambientalmente correta, envolve a inclusão de práticas a fim de reduzirem seus impactos ambientais e, consequentemente, implicando em mudanças em seus processos produtivos.

A inserção dessas práticas no âmbito das organizações, além de contemplar variáveis essenciais de competitividade, "demanda de seus participantes uma complexidade cognitiva mais elevada para interpretação de suas dimensões sistêmicas e de seus múltiplos critérios associados à economia, à sociedade e ao meio ambiente" (NOBRE et al., 2013). De maneira complementar, alternativas inovadoras sustentáveis tornam-se potenciais de oportunidade de geração de valores e viabilizam a expansão de possibilidades de produção, de forma a maximizar possíveis soluções imbricadas nos âmbitos econômico, social e ambiental (BOSZCZOWSKI et al., 2012). 
No aspecto ambiental, a Economia Circular (EC) apontou como uma concepção da relação meio ambiente e economia (SU et al., 2013; ABADIA et al., 2016). O conceito de EC foi cunhado por Pearce et al. (1990) e trata-se de um sistema regenerativo no processo de entrada de recursos e saída dos produtos. 0 alcance dessa dinâmica de "fechar o ciclo de recursos" pode ser realizado por meio de designs, manutenção, reparos, reutilizações, remanufaturas, reformas e reciclagem (ZUCCHELLA et al., 2018).

Ao relacionar meio ambiente e economia, a EC congrega formato que traduz a redução de custos empresariais, além de integrar eficiência econômica e ecológica. Neste sentido, surge o termo Ecoeficiência que traduz essa dinâmica (VELLANI et al., 2009). O conceito de EC admite diversas escalas para os grandes, médios e pequenos negócios, para indivíduos e organizações, no âmbito local ou global, contribuindo para melhoria do bem-estar do sistema. A adoção de uma EC representa mais do que ajustes para redução de impactos negativos da economia linear, constitui a aplicação de uma produção sistêmica que constrói adaptações em longo-prazo, gera oportunidades econômicas e de negócios e, ao mesmo tempo, gera benefícios ambientais e sociais (EMF, 2017).

O modelo de negócio circular, entendido como aquele que torna o lucro compatível com o futuro do planeta, fechando o ciclo de recursos, trata-se de uma valiosa contribuição para a agenda de sustentabilidade. Inovações de sucesso na EC envolvem atores diferenciados e engajados no desempenho comum em materializar uma visão de negócio ecossistêmico (ZUCCHELLA et al., 2018). Ceglia (2020) aponta que a adoção da EC é complexa, sendo necessário um olhar abrangente para a questão e considerar, principalmente, os aspectos econômicos, sociais e ambientais.

Nesse sentido, o fluxo que envolve o reuso cíclico de materiais na EC pode seguir três vertentes, a reciclagem (recycling), a subciclagem (downcycling) e o processo de agregar valor por meio do upcycling. Conforme Moreira et al. (2018), no processo de reciclagem (recycling), em virtude dos procedimentos utilizados no processo, considera-se haver um downcycling (ou "subciclagem"). Dito de outra forma, no processo de reciclagem, a qualidade do material vai se degradando a cada ciclo. No Upcycling ocorre o contrário, já que resíduos são transformados em matéria prima, sem intervenção química, proporcionando menor impacto ao meio ambiente. O Upcycling, segundo Shoup (2008), consiste em um modelo de produção em que matérias primas residuais, que seriam descartadas, são utilizadas em processos produtivos de novos itens, agregando valor a eles sem alterar as suas características principais.

A técnica de Upcycling, para Shoup (2008), agrega às peças produzidas uma qualidade igual ou melhor aos antigos produtos. Outro fator relevante é que a técnica minimiza o impacto de resíduos destinados aos aterros sanitários (ECYCLE, 2008). Além de subsidiar a conservação do ambiente, o modelo de Upcycling traz uma gama maior de benefícios tais como: melhor qualidade; design único feito, muitas das vezes, de forma artesanal; produtos com edições limitadas, considerando as especificidades e os formatos da matéria prima.

Trata-se de um processo com elevado potencial criativo e inovador, cujo modelo já é implementado em muitos seguimentos empresariais como: (i) moda, na reutilização de produtos que seriam descartados sendo transformados e customizados (KIM, 2014; LUCIETTI et al., 2018; SOUZA et al., 2015); (ii) lixo, 
transformação de embalagens e outros tipos de materiais em produtos úteis, agregando valor para elementos potencialmente descartáveis (RICHARDSON, 2011; MOREIRA et al., 2018); (iii) Projetos Arquitetônicos, a reutilização de produtos classificados como descartáveis em projetos arquitetônicos e ambientes (PEREIRA, 2017). Em todas essas iniciativas, o valor agregado ao produto inclui, sobretudo, a sustentabilidade e a ecoeficiência.

Sob o aspecto específico da indústria têxtil, Ceglia (2020) além de demonstrar a complexidade da EC, enfatizou que a lógica da economia linear que nutre o mercado do fast fashion dificulta a inserção de iniciativas, principalmente, de processos criativos de EC no setor da moda, pois estes atuam em escalas menores de produção, mais demoradas e que resultam em produtos com custo mais elevado. Contudo, A EC criativa trata-se de uma possibilidade de reuso de materiais de forma limpa, com menos impacto ao meio ambiente e, ainda, realizada ora com parcerias colaborativas com pequenas marcas ora utilizando a criatividade individual de atores inseridos nas organizações (CEGLIA, 2020).

Para Ceglia (2020), utilizar-se da EC por meio do upcycling, por exemplo, pode ser alternativa de transformação de passivos ambientais em ativos econômicos.

Os percursos percorridos pelas organizações na adoção de uma postura responsável em relação ao meio ambiente e ao gerenciamento dos seus impactos exigem a aplicação de elevado aporte financeiro, "devendo-se ter constante preocupação em controlá-los" (SANTOS et al., 2001). Assim, na tentativa de melhor compreender essa dinâmica, dissertou-se na seção seguinte sobre o passivo ambiental na Indústria Têxtil.

\section{Passivo ambiental na Indústria Têxtil}

O passivo ambiental é composto pelo conjunto de obrigações com gastos ambientais que incidem sobre a empresa no seu processo de produção, sendo aplicável para encargos relacionados à prevenção, redução ou retificação de danos ambientais (SANTOS et al., 2001; RIBEIRO, 2010). Ribeiro (2010) considera que o passivo ambiental se trata de resultados econômicos tanto benéficos quanto aqueles que sejam sacrificados com o intuito de realizar a preservação, proteção e recuperação do meio ambiente, permitindo compatibilizar tais ações com o desempenho econômico das empresas. Ao apreciar que a indústria têxtil congrega, portanto, elevado impacto ao meio ambiente em toda a sua cadeia de produção, considerou-se que o rastreio e controles de tais impactos possui alta complexidade (BERLIN, 2014). Dessa forma, avaliando a multidisciplinaridade da indústria têxtil, cujos processos englobam desde a plantação de sementes para a geração da matéria-prima até o produto pronto nas passarelas e vitrines (BERLIN, 2014), fez-se o recorte do processo em análise no presente trabalho, limitando-se aos impactos ocasionados pelo descarte final dos resíduos sólidos.

O Brasil é o quinto maior produtor têxtil e quarto maior produtor de vestuário, sendo que no ano de 2012 produziu, respectivamente, 2.143 e 1.215 toneladas nesses segmentos (ABIT, 2018). A geração anual de resíduos aproxima de 170 toneladas, sendo que $80 \%$ disso são descartados em aterros e lixões. “Considerando apenas o descarte de vestuário, entre 9,8 bilhões de peças de vestuário produzidas em um 
ano e estima-se que mais de 150 milhões não tenham destino definido" (AMARAL et al., 2018). Mesmo não sendo possível contabilizar o descarte têxtil doméstico, ele está incluído nas 183.488 toneladas de resíduos sólidos coletados diariamente no Brasil, dado este apontado na Pesquisa Nacional de Saneamento Básico PNSB 2008 (IBGE, 2010).

No âmbito legal, a Lei no 10.650, de 16 de abril de 2003, que “Dispõe sobre o acesso público aos dados e informações existentes nos órgãos e entidades integrantes do Sisnama" - Sistema Nacional de Meio Ambiente do Conselho Nacional do Meio Ambiente - Ministério do Meio Ambiente, passa a prever a prestação periódica de informações por parte de entidades privadas sobre os potenciais e efetivos impactos ambientais de suas atividades (BRASIL, 2019). Em consonância com essa política, no ano de 2010 o Governo instituiu a Política Nacional de Resíduos Sólidos -PNRS - Lei no 12.305, de 2 de agosto de 2010 (BRASIL, 2019). Com a implementação da PNRS, priorizou-se o tratamento e não geração de resíduos sólidos e sobras do processo produtivo. A PNRS é um marco regulatório brasileiro que, além de definir um regime de responsabilidade compartilhada em relação ao ciclo de vida de diversos produtos, foi responsável por deliberar sobre os procedimentos a serem considerados pelas empresas para o provimento da adequada destinação dos resíduos sólidos (DEMAJOROVIC et al., 2013). Contudo, mesmo sendo a PNRS uma importante ferramenta para a compreensão da necessidade de implementação de ações empresariais favoráveis ao processo de reuso e reciclagem, na indústria têxtil essa realidade ainda está muito longe de ser alcançada (ZONATTI, 2016).

Neste processo, identificar o dano ambiental torna-se o primeiro momento de implementação de uma proposta de gestão ambiental. A combinação de elementos de identificação desses danos refletirá no patrimônio da empresa, evidenciando os impactos causados e sendo possível mensurá-los por meio do passivo ambiental (FERREIRA, 2011; MARQUES et al., 2016). A compreensão dos pressupostos que envolvem o significado do tema "meio ambiente" só será possível a partir de um entendimento que transpassa a contabilidade, que envolva, sobretudo, a compreensão de aspectos sociais, culturais e educacionais imbuídos na questão (FERREIRA, 2011).

Contudo, os dados que são divulgados pelas empresas brasileiras, em relatórios anuais ou de sustentabilidade, em relação às questões ambientais, não são, necessariamente, uma realidade abordada de forma uniforme e isso dificulta a sua padronização e avaliação. Considera-se que "devido à assimetria de informação entre as partes interessadas e os altos executivos, as informações sobre o meio ambiente podem ser facilmente manipuladas, o que resulta na divulgação seletiva para gerenciar impressões" (VOGT et al., 2016). Conforme pontuado por Ribeiro (2010) "a elaboração dos documentos relacionados ao meio ambiente demanda recursos e tempo", mas o posicionamento organizacional em relação a sua postura e preocupação com a questão ambiental, bem como com a sociedade presente e futura, será reforçada com a divulgação de informações sobre investimentos e interação com o patrimônio natural. Em resumo "os dados físicos sobre os programas de melhorias e aperfeiçoamento constituiriam as informações de natureza qualitativa sobre o empenho da organização" em relação aos seus impactos ambientais (RIBEIRO, 2010).

Em comparação a outro país, um estudo realizado na Holanda (BURGWAL et al., 2014) apontou que 
mesmo não possuindo legislações específicas sobre a divulgação das informações ambientais, grande parte das empresas holandesas as realizam devido ao funcionamento autorregulador e autodisciplinador dos negócios no país, especificamente. Assim, devido a esse funcionamento autorregulador dos negócios, as empresas holandesas necessitam tomar decisões acerca do nível de divulgação das informações ambientais. As divulgações dessas informações pelas empresas holandesas dão destaque à preocupação em tornar tais dados conteúdo qualificador de desempenho e engajamento socioambiental.

Santos et al. (2001) constatou em sua pesquisa que apenas $20 \%$ das empresas brasileiras utilizaram a contabilidade na gestão ambiental e confirmou a sua hipótese de que "a maioria das companhias ainda desconhece as vantagens que a utilização da contabilidade ambiental pode trazer para seus negócios". Já Santos et al. (2017) apontaram que 50\% do grupo de empresas pesquisadas realizaram o lançamento dos passivos e contingências ambientais nas informações divulgadas nos anos de 2014 e 2015, mas propalaram tais informações por meio de indicadores disponíveis nos seus relatórios anuais.

Tais apontamentos podem ser explicados pelo fato de que as empresas têm dificuldade em realizarem a avaliação dos seus custos ambientais, principalmente no que diz respeito a identificação e mensuração. Grande parte dos custos ambientais pode ser enquadrado em classificações como custos indiretos e fixos do processo de fabricação, ou ainda, ocorrerem simultaneamente ao processo produtivo normal o que dificulta a análise contábil (RIBEIRO, 2010).

\section{METODOLOGIA}

Esta pesquisa se caracteriza como qualitativa e descritiva, de caráter exploratório (GIL, 1999). A compreensão dos termos sustentabilidade, EC, e passivo ambiental foi realizada por meio de pesquisa bibliográfica sobre as temáticas. Na intenção de investigar a EC como alternativa para o lançamento estrutural do passivo ambiental da indústria têxtil, realizou-se uma pesquisa documental delimitando como corpus analítico os dois últimos relatórios publicados eletronicamente das empresas (Demonstrações Financeiras, Relatórios Anuais e Relatórios de Sustentabilidade) e, também, outros materiais institucionais divulgados eletronicamente que continham informações consideradas relevantes para os resultados, todos considerados como documentos de "segunda mão" (GIL, 1999). Com a aplicação deste método, buscou-se “identificar informações factuais nos documentos a partir de questões e hipóteses de interesse" (CAULLEY, 1981 citado por LÜDKE et al., 1986). Além disso, foi possível identificar outras informações qualitativas das empresas que, muitas vezes, não ficam disponibilizadas nos relatórios.

Para levantar as empresas a serem analisadas utilizou-se a listagem da Associação Brasileira do Varejo Têxtil - ABVTEX, uma associação de redes do varejo de moda, responsável pela interlocução do setor às autoridades governamentais e não governamentais, associações, imprensa e sociedade. O estudo avaliou, para a escolha das empresas, aquelas vinculadas à ABVTEX, considerando que a associação divulga como um de seus pilares "[...]combate à informalidade e o desenvolvimento sustentável da cadeia produtiva que abastece o varejo de moda [...]". Da listagem anterior, foram selecionadas três empresas com modelos de negócios similares bem como já possuírem iniciativas de EC. As empresas selecionadas foram: C\&A, Farm 
(Grupo Soma) e Lojas Renner.

Os dados coletados foram analisados através da técnica de análise de conteúdo de Bardin (1995), com o intuito de descrever o conteúdo das mensagens que possibilitam inferências e que serão categorizadas em quadros. No processo de análise, foram consideradas as informações contidas nos documentos sobre sustentabilidade, economia circular e evidências de lançamento dessas informações, bem como do passivo ambiental nos relatórios analisados.

\section{RESULTADOS}

Na intenção de responder o questionamento da pesquisa e, também, descrever os tipos de EC, dos lançamentos estruturais de iniciativas socioambientais e do passivo ambiental das empresas pesquisadas, apresentamos nesta seção os resultados da pesquisa.

Por meio da análise documental dos relatórios e outros materiais institucionais disponibilizados eletronicamente das empresas C\&A, Farm (Grupo Soma) e Renner constatou-se que todas as empresas têm seus negócios consolidados no Brasil. Em relação aos aspectos que envolvem o engajamento socioambiental das empresas, destacou-se:

(i) De acordo com os relatórios analisados e website da empresa, as primeiras iniciativas ambientais da C\&A ocorreram em 2007 com a criação de Comitê para iniciativas ambientais. Em 2008 a empresa mapeou os impactos ambientais e sociais, tendo sido um de seus primeiros passos buscar a identificação dos danos causados por ela para, somente então, iniciar sua estratégia voltada a sustentabilidade e emissão de documentos relacionados ao meio ambiente. Desde de 2009 a C\&A emitiu relatórios de sustentabilidade conforme as diretrizes da Global Reporting Initiative (GRI), salvo em 2014 que não houve a publicação. A C\&A inaugurou em 2009 sua primeira loja-verde no Brasil chamada de C\&A Eco, a segunda da empresa em nível mundial. Nessa loja há o espaço do cliente que reúne produtos de impacto ambiental reduzido, que inclui roupas de algodão orgânico e de malha pet, chinelos de pneu reciclado e sacolas retornáveis, conforme relatório de 2009 fornecido pela empresa. A empresa também criou a loja-laboratório a fim de identificar, além de outros pontos, as percepções da sustentabilidade, bem como a receptividade de seus clientes a produtos que possuem menor impacto ambiental. Nos valores organizacionais da empresa, relacionam-se a ética, a transparência, a responsabilidade social, a inovação, a diversão e a paixão por pessoas.

(ii) A FARM, conforme descrito nas informações de websites, é engajada em projetos sustentáveis e políticas de responsabilidade socioambiental. O grupo Soma, que incorpora a Farm, firmou compromisso com a Agenda 2030, deliberada por líderes mundiais no ano de 2015. O plano de ação da Agenda 2030 envolve a erradicação da pobreza, a proteção do planeta e a garantia que as pessoas alcancem a paz e a prosperidade. Em relação ao Desenvolvimento Sustentável Global, há outros dezessete objetivos. Além disso, o grupo deliberou como meta para 2020 seis estratégias para a sua política de responsabilidade socioambiental, sendo elas: (i) Otimizar a gestão de resíduos sólidos, firmando parcerias com o Movimento Lixo Zero e Cooperativa Transformando para todas as unidades; (ii) Incluir cláusula de responsabilidade socioambiental em contratos com fornecedores; (iii) Acompanhar os indicadores de sustentabilidade dos 
fornecedores; (iv) Aumentar a utilização de matérias primas de origem sustentável/menor impacto ambiental em todas as marcas do grupo; (v) Lançar relatório de sustentabilidade do grupo e (vi) Publicar lista de fornecedores no site. $\mathrm{O}$ grupo Soma preconiza, ainda, o trabalho voltado para a diminuição dos impactos ambientais e o alcance de um impacto social positivo.

Outra iniciativa de engajamento socioambiental foi a criação do Clube Farm, um programa para plantio de árvores que conta com aproximadamente 7.500 mil assinantes. Os assinantes do Club Farm pagam uma quantia de $\mathrm{R} \$ 10,00$ (dez reais) mensais e assim contribuem para reflorestamento de áreas como a Amazônia e a mata atlântica, além de terem acesso e descontos exclusivos da marca.

(iii) Conforme destacado nos relatórios e website da Lojas Renner S.A., a gestão e a condução dos seus negócios são orientadas pelos princípios da sustentabilidade para a promoção e a entrega de uma moda responsável à sociedade, por meio do equilíbrio entre as questões econômicas, sociais, ambientais e de governança corporativa nas operações. Neste sentido, além dos resultados financeiros, a empresa busca o desenvolvimento social e a redução dos impactos ambientais, almejando atuar com as melhores práticas de governança corporativa. A primeira loja dentro do projeto Renner Sustentável teve sua abertura em 2014, no Riomar Shopping Fortaleza. Comprometida com políticas de sustentabilidade, a Lojas Renner possui princípios, compromissos voluntários e diretrizes estratégicas relacionadas a moda sustentável. Entre seus princípios, estão: Engajamento para a sustentabilidade e melhoria contínua; Desenvolvimento social; Preservação ambiental; e Econômico. Entre seus compromissos voluntários estão: Pacto global das nações unidas; Princípios do empoderamento das mulheres e Pacto pela erradicação do trabalho escravo. Suas diretrizes estratégias, por sua vez, consistem em: Fornecedores responsáveis; Gestão ecoficiente; Engajamento de colaboradores, comunidades e clientes; e Produtos e serviços sustentáveis.

Em 2018, o compromisso da Lojas Renner com uma moda cada vez mais responsável ganhou força. $\mathrm{O}$ ano foi marcado pelo lançamento do Selo Re, criado para representar o comprometimento da companhia em fazer este tema presente na vida de todos os públicos com que se relaciona. Junto ao lançamento do Selo Re, a Companhia assumiu metas e compromissos até 2021: $80 \%$ de produtos menos impactantes, sendo $100 \%$ de algodão certificado; $100 \%$ da cadeia nacional e internacional de revenda com certificação socioambiental; $75 \%$ do consumo de energia corporativo será de fontes de energias renováveis; $20 \%$ de redução das emissões absolutas de CO2 frente a 2017.

No que diz respeito às iniciativas de EC e possíveis lançamentos nos relatórios das empresas pesquisadas, destacou-se: (i) Na C\&A, destacam-se as iniciativas de comercialização de produtos cuja matéria prima é composta por pneus; a parcerias com ONGs na doação de materiais para a produção de bolsas e chaveiros; e, recentemente, a implementação do Projeto Reciclo por meio do recolhimento de peças usadas. Em relação ao passivo ambiental, notou-se que a empresa no ano de 2009 promoveu iniciativas para a mensuração dos seus impactos em toda a cadeia produtiva, que se trata do primeiro passo à condução de uma correta Gestão Ambiental (FERREIRA, 2011; MARQUES et al., 2016), bem como com a legislação de transparência ambiental e a PNRS. A partir desse ano, notou-se uma evolução no que diz respeito ao crescimento de ações socioambientais da $C \& A$, bem como no aumento de investimentos na área. 
Em 2010 a C\&A criou o Comitê Estratégico de Sustentabilidade e em 2011 o primeiro Painel de diálogo com Stakeholders sobre sustentabilidade. No ano seguinte criou a Plataforma de Sustentabilidade e em 2013 elaborou o plano corporativo de resíduos sólidos baseado na lei nacional de resíduos sólidos. Ademais, a empresa criou um sistema no qual as lojas poderiam inserir informações sobre os resíduos e possíveis parceiros para destinação. Em 2015 a organização elaborou uma estratégia global de sustentabilidade e tornou-se signatária do Pacto Global da Organização das Nações Unidas. A partir de 2016 a varejista se concentrou em modelos de economia circular que vão além da reciclagem e aproximam-se do processo de Upcycling - os uniformes antigos dos funcionários da empresa, por exemplo, passaram a ser doados para ONGs que confeccionam bolsas e chaveiros.

Outra prática adotada pela empresa no ano de 2017 foi o lançamento do Projeto Reciclo, que tem como objetivo a prática de logística reversa de têxteis pós-consumo. O projeto tem a pretensão de evitar que peças de roupas usadas terminem em aterros sanitários. Embora ainda seja um projeto pontual, por englobar apenas peças específicas e ter pontos de coleta apenas em lojas que comercializam tais peças, a empresa assumiu o compromisso de não enviar resíduos para aterros de suas operações até o ano de 2025 . 0 progresso desse compromisso ainda será mensurado. Nota-se, portanto, que a C\&A detém elevado empenho e transparência em relação às ações socioambientais, utilizando-se de valores investidos nessas áreas para demonstrar sua evolução. Entretanto, ainda que as informações financeiras relacionadas ao tema estejam localizadas em seus relatórios de sustentabilidade, estas não são evidenciadas diretamente nos relatórios contábeis da empresa.

(ii) A empresa Farm, demonstrou a adoção de EC, modelo de produção Upcycling iniciado no ano de 2017 por meio da parceria com outra empresa de menor porte especializada no modelo. Em 2017, a estimativa de geração de resíduos de corte da Farm era de cerca 64 toneladas por mês da produção. Além disso, cerca 20 mil peças produzidas voltavam das lojas da marca semestralmente por apresentarem pequenos defeitos. Ao perceberem que todo esse resíduo gerado poderia ser utilizado como matéria prima de qualidade no contexto do Upcycling, os gestores da empresa fizeram parceria com o projeto Re-Roupa, cuja metodologia envolve o modelo.

Dessa parceria, realizou-se no ano de 2017, uma coleção inteira de roupas confeccionadas a partir desses resíduos. No processo, foram disponibilizadas 600 peças como matéria prima, obtendo-se 200 novas peças produzidas por Upcycling. O custo médio dessas novas peças foi mais elevado do que de coleções comuns da marca, mas o giro da coleção foi positivo, segundo seus gestores. Conforme dados da empresa, o giro médio de uma coleção é de $40 \%$ na primeira semana de lançamento. Na coleção que utilizou o Upcycling como meio de produção, o giro foi de $70 \%$. Atualmente, a empresa lança coleções específicas de reuso de materiais, a Re-Farm e a Re-Farm Jeans.

Constatou-se que o grupo Soma possui outras iniciativas condizentes com o método de Upcycling. Uma delas é a realização de parcerias com a Rede Asta, a Oficina Chic Hippie, o Banco de Tecidos e Nosso Tecido para o reaproveitamento do corte de tecidos e/ou sobras de matérias prima e aviamento. 0 grupo também firmou parceria com o site Enjoei, incentivando o reuso de roupa em bom estado. Ainda que a Farm 
não possua registro sobre o passivo ambiental da sua cadeia produtiva, o grupo Soma, do qual faz parte, realiza a divulgação de informações sobre as metas a serem alcançadas na busca pela sustentabilidade ambiental das suas marcas.

O grupo Soma, nos últimos dois anos, realizou a revisão dos seus impactos ambientais passando a economizar dois milhões de litros de água o tratamento do jeans, realizar doações de $100 \%$ do resíduo têxtil gerado, fornecedores com certificação ABVTEX, investir cerca de $\mathrm{R} \$ 1,6$ milhão em projetos socioambientais, plantar cerca de 65.000 árvores, realizar a adesão ao projeto de economia compartilhada de vestuário, e possuir grande parte da cadeia auditada.

As informações da Farm (Grupo Soma) não são agrupadas em relatórios oficiais da empresa ou do grupo, sendo grande parte disponível nos próprios websites em uma área denominada 'área corporativa de Sustentabilidade' ou no ambiente destinado aos investidores. Nas informações avaliadas, não foram localizados lançamentos estruturais acerca do passivo ambiental da empresa. Sobre as informações acerca dos recursos investidos em iniciativas socioambientais, estas são pontuais e não estão dispostas em documentos estruturados.

(iii) Desde 2017, a Renner em parceria com a Universidade de São Paulo (USP), foi desenvolvido, junto aos fornecedores de revenda da Renner e Youcom das cadeias de malha, jeans e tecido plano, um projeto com o objetivo de reduzir a geração de resíduos têxteis pela abordagem de produção mais limpa $(\mathrm{P}+\mathrm{L})$.

Desta forma, 47 toneladas de resíduos deixaram de ser gerados e 700 toneladas deixaram de ser destinadas a aterros e ganharam novas utilidades via reciclagem ou reutilização. Além disso, em 2018, aproximadamente $10 \%$ do total das peças produzidas foram feitas com matérias-primas e processos menos impactantes. Em linha com a meta de 100\% do algodão certificado até 2021, em 2018, mais de 8 milhões de peças foram produzidas com esta matéria-prima, representando $15 \%$ do total de itens em algodão.

A solidez da estratégia e o avanço na adoção de práticas mais sustentáveis no modelo de negócio das Lojas Renner têm sido reconhecidas pelas principais ferramentas de avaliação da sustentabilidade empresarial. A empresa foi selecionada pelo 5o ano consecutivo para o Índice de Sustentabilidade Empresarial da B3 e para o Dow Jones Sustainability Index (DJSI), que conta com 317 empresas de 30 países e apenas sete brasileiras. Com o aprendizado ao longo dos anos, as Lojas Renner têm construído um portfólio cada vez maior e diversificado de produtos menos impactantes ao meio ambiente, como é o caso dos Biquínis Upcycling, feitos com a reinserção criativa no ciclo de produção de matérias-primas que seriam descartadas.

Além disso, para peças de roupa que já não têm mais utilidade para os clientes, tendo sido compradas nas lojas da Renner ou não, a companhia oferece, desde 2017, um serviço de coleta em que as peças são destinadas para reciclagem ou para reutilização por Upcycling ou doação. Em relação aos Balanços Anuais das Lojas Renner, foram detectados no Balanço Anual 2019 o lançamento de investimentos em ações de compensação ambiental, contudo não foram localizadas informações acerca do impacto ambiental ocasionado pela empresa para o exercício de sua atividade. A empresa detém um grande número de programas considerados como práticas sustentáveis e possui indicadores ou metas anuais relacionadas à 
diminuição de resíduos ou impactos de produção e operação até o ano de 2021.

Ao analisar os relatórios, entrevistas, websites e demais documentos das três empresas pesquisadas, foram constatadas evidências sustentáveis, bem como de EC por meio da adoção do modelo de produção limpo, a exemplo do Upcycling. Outras iniciativas com vistas à redução dos impactos ambientais, ecoeficiência da produção e responsabilidade foram detectadas nas três empresas, o que tem proporcionado, inclusive, o recebimento de prêmios.

\section{DISCUSSÃO}

As três empresas pesquisadas, C\&A, Farm (Grupo Soma) e Renner apresentaram dados relacionados a gastos com iniciativas socioambientais, porém não o fazem de forma global e dessa forma não utilizam a Contabilidade Ambiental como potencial auxílio aos gestores, inclusive, para a formulação de políticas e gestão ambiental da cadeia produtiva, em conformidade com o que pontua Santos et al. (2001). A C\&A menciona suas informações financeiras relacionadas ao tema nos relatórios de sustentabilidade, embora tais dados não sejam diretamente evidenciados nas demonstrações financeiras. A empresa, conforme informação contida no próprio site, não divulga suas informações financeiras de forma global e as demonstrações realizadas dizem respeito apenas ao que é exigido nos regulamentos nacionais.

Notou-se que as empresas estão realizando parcerias positivas em pesquisas com vistas à implementação de estratégias que reduzam ou anulem a geração final de resíduos sólidos na perspectiva da EC cunhada por Peace et al. (1990) e conforme concepções de Su et al. (2013), Abadia et al. (2016), Zucchella et al. (2018). O engajamento sustentável e iniciativas de EC foram descritos no Quadro 1.

Quadro 1: Engajamento Sustentável e Iniciativas de Economia Circular.

\begin{tabular}{|l|l|l|l|}
\hline & Lojas Renner & C\&A & $\begin{array}{l}\text { Farm } \\
\text { Grupo Soma }\end{array}$ \\
\hline Lançamento de linhas de moda sustentável & & $\mathrm{X}$ & $\mathrm{X}$ \\
\hline Divulgação de uma imagem sustentável & $\mathrm{X}$ & $\mathrm{X}$ \\
\hline Produção mais limpa & $\mathrm{X}$ & $\mathrm{X}$ & $\mathrm{X}$ \\
\hline Metas e compromissos de sustentabilidade & $\mathrm{X}$ & $\mathrm{X}$ & $\mathrm{X}$ \\
\hline Parceria com empresa de Upcycling & $\mathrm{X}$ & $\mathrm{X}$ & $\mathrm{X}$ \\
\hline Parceria com empresa de Downcycling & $\mathrm{X}$ & $\mathrm{X}$ & \\
\hline Parceria com ONG's que usam a técnica de Upcycling & $\mathrm{X}$ & $\mathrm{X}$ & \\
\hline Iniciativas de logística reversa & $\mathrm{X}$ & $\mathrm{X}$ & $\mathrm{X}$ \\
\hline Procura de fornecedores responsáveis & $\mathrm{X}$ & $\mathrm{X}$ & $\mathrm{X}$ \\
\hline Divulgação das ações socioambientais & $\mathrm{X}$ & $\mathrm{X}$ \\
\hline Uso de matérias-primas menos impactantes & $\mathrm{X}$ & $\mathrm{X}$ \\
\hline Gestão de resíduos sólidos & $\mathrm{X}$ & $\mathrm{X}$ \\
\hline Loja sustentável & $\mathrm{X}$ & $\mathrm{X}$ \\
\hline Gestão ecoeficiente & $\mathrm{X}$ & $\mathrm{X}$ & $\mathrm{X}$ \\
\hline Emissão de relatórios de sustentabilidade & $\mathrm{X}$ & $\mathrm{X}$ \\
\hline Mapeamento dos impactos ambientais & $\mathrm{X}$ & $\mathrm{X}$ \\
\hline Comitê de sustentabilidade & $\mathrm{X}$ & \\
\hline
\end{tabular}

Considerando os impactos ambientais da indústria têxtil em toda a sua cadeia de produção, o engajamento socioambiental das empresas do setor, bem como o investimento e compromisso com alternativas que minimizem os seus impactos ambientais tornam-se movimentos necessários para que a sociedade avance e as organizações consigam congregar iniciativas de uma moderna gestão ambiental, 
adaptando-se aos preceitos do triple bottom line, na perspectiva de Abreu et al. (2013), além da promoção da ecoeficiência (VELLANI et al., 2009). De modo geral, todas as empresas divulgam suas ações socioambientais, bem como os projetos voltados para iniciativas que visem minimizar seus impactos, principalmente por meio de parcerias com empresas de menor porte (CEGLIA, 2020). Diversas podem ser as motivações desde Marketing digital, Greenwashing, pressão da sociedade, preocupação em resolver o problema do passivo ambiental, revisão de valores organizacionais, externalizar o passivo ambiental, construir a imagem de uma empresa sustentável, otimização de processos para aumento do lucro, conscientização sobre sustentabilidade, revisão de processos, busca de oportunidades de novos produtos e mercados, dentre outros. Porém, vale expor que apenas a C\&A demonstrou de maneira descritiva, nos relatórios de sustentabilidade, os impactos negativos da sua atividade produtiva ao meio ambiente. Os principais Projetos e Iniciativas Socioambientais foram descritos no Quadro 2.

Quadro 2: Projetos e Iniciativas Socioambientais.

\begin{tabular}{|l|l|}
\hline Renner & $\begin{array}{l}\text { EcoEstilo } \\
\text { Projeto Renner Sustentável } \\
\text { Lançamento do Selo Re }\end{array}$ \\
\hline C\&A & $\begin{array}{l}\text { Projeto C\&A Aposta_ } \\
\text { Loja-laboratório } \\
\text { Relatório Global de Sustentabilidade } \\
\text { Peças com o Certificado Cradle to Cradle (C2C) } \\
\text { Campanha 'VistaAMudança' } \\
\text { Projeto Reciclo }\end{array}$ \\
\hline Farm & $\begin{array}{l}\text { Projeto Re-Roupa } \\
\text { Compromisso com a Agenda 2030 } \\
\text { Marca Guardiã da Água } \\
\text { Mulheres do Sul Global } \\
\text { Parcerias com a Rede Asta, a Oficina Chic Hippie, o Banco de Tecidos, Nosso Tecido }\end{array}$ \\
\hline
\end{tabular}

As evidências de EC, por meio da adoção tanto do Upcycling na perspectiva de Shoup (2008) quanto de outras iniciativas, foram detectadas pontualmente na C\&A e de forma mais explícita nas empresas Renner e Farm. O gerenciamento de todo ou parte dos impactos ocasionados pelas empresas da indústria têxtil é fator necessário ao alinhamento responsável tanto no que diz respeito à legislação brasileira sobre a temática quanto à pró-atividade ambiental descrita por Abreu et al. (2013). Com essas informações bem estruturadas, os investimentos realizados diretamente ou via parcerias relacionadas à EC, assim como as demais iniciativas sustentáveis poderiam ser lançadas de maneira a proporcionar uma visualização estrutural, em formato claro e consistente, ampliando o engajamento uniforme nas dimensões ambiental, social e econômica (NOBRE et al., 2013).

Concluiu-se, portanto, que a EC, seja por meio da adoção do modelo Upcycling descrito por Shoup (2008), seja por meio de outra estratégia pode ser apontada como alternativa para o passivo ambiental das empresas. Para isso, as organizações devem inserir o lançamento estrutural dos investimentos realizados no processo em toda a sua cadeia produtiva permitindo assim, uma melhor visualização dos dados físicos nos seus relatórios contábeis. Nos relatórios analisados das três empresas, constatou-se no relatório referente ao Balanço Anual da Renner 2019, o lançamento de investimentos com ações de compensação ambiental o que, na perspectiva de Ribeiro (2010) são consideradas informações qualitativas sobre o comprometimento 
das empresas em relação aos seus impactos ambientais, que também devem ser lançados compondo o conjunto do passivo ambiental. Sob esse aspecto, não foram detectadas informações relacionadas aos impactos ambientais das empresas pesquisadas em seus relatórios financeiros o que impossibilita uma análise mais adequada e comparativa tanto com os indicadores de investimentos em ações de compensação quanto com as iniciativas e programas socioambientais detectadas já que, na indústria têxtil especificamente, o impacto ao meio ambiente é ocasionado em toda a cadeia (BERLIM, 2014).

Sob o aspecto da sustentabilidade no âmbito da indústria têxtil, a EC e seu modelo Upcycling, na perspectiva de Ecycle (2008), Shoup (2008) e Moreira et al. (2008), além de minimizar o impacto de resíduos destinados aos aterros sanitários, foi vislumbrado como um modelo que traduz eficiência econômica e ecológica, ou seja, proporciona a ecoeficiência das empresas do setor têxtil, já que é capaz de gerar uma gama maior de benefícios às empresas que o adotam, por sua elevada potencialidade inovadora e criativa. Assim, considerando todo o impacto ocasionado no setor, o Upcycling traduz uma opção condizente com o real significado de "sustentabilidade", ou seja, apresenta-se como uma nova prática para o processo produtivo com vistas à redução dos impactos ambientais (ABREU et al., 2013).

\section{CONCLUSÕES}

Este estudo investigou a EC e o passivo ambiental da indústria têxtil. Na análise de três empresas do setor da moda brasileiro, notou-se que há um movimento crescente nas divulgações das ações de sustentabilidade e iniciativas redutoras de impactos causados pelas organizações ao meio ambiente, porém algumas empresas não divulgam os impactos negativos da sua atividade produtiva ou não realizam o lançamento dessas informações de forma estruturada em relatórios financeiros.

Ao analisar os relatórios das empresas C\&A, Farm e Renner foram detectadas evidências de utilização da EC com a inserção de alternadas na cadeia que minimizam os impactos dos seus resíduos sólidos finais. As técnicas utilizadas pelas empresas são amplas e envolvem, em sua maioria, parcerias realizadas com projetos ou empresas de menor porte. Embora as empresas estudadas venham direcionando cada vez mais esforços para a sustentabilidade de sua cadeia produtiva e despendendo mais atenção pela área, foram localizadas em uma empresa apenas as classificações de tais dados como lançamentos contábeis. Nas demais, constatou-se que não está havendo uma utilização eficiente dessas informações, principalmente no que diz respeito aos relatórios/balanços financeiros ou de contabilidade. Do mesmo modo, não foram detectados os lançamentos específicos acerca do passivo ambiental das empresas. Uma empresa apenas introduziu dados explicativos acerca dos seus impactos ambientais, sem detalhamento.

A indústria têxtil gera impacto em toda a sua cadeia de produção e, mesmo sendo difícil a mensuração desses impactos, pode avançar na divulgação e transparência dessas informações para a sociedade, utilizando-se dos investimentos realizados em alternativas sustentáveis e de EC para contrapor com todo o seu dano ambiental, por meio de formatos bem estruturados e disponibilizados nos seus relatórios. Espera-se que os dados encontrados dos cases analisados nesta pesquisa possam incentivar outras organizações a aplicar iniciativas similares relacionadas principalmente ao reuso de materiais. Espera-se, 
ainda, que os estudos desta temática que envolve o setor têxtil, especificamente, avancem de forma a ampliar as discussões a respeito dos resíduos têxteis e sustentabilidade e, assim, caminhar para o preenchimento da lacuna apontada por Ceglia (2020). Para que se consiga inferir o nível do compromisso organizacional no que diz respeito à atuação em formato positivo para sociedade e limpo para o meio ambiente, é preciso que as informações do passivo ambiental das organizações estejam objetivamente especificadas em seus relatórios.

Por fim, pontua-se que a principal limitação desta pesquisa está relacionada ao baixo número de empresas analisadas, entretanto, buscou-se realizar as análises em profundidade com vistas a responder apropriadamente o questionamento inicial proposto. Considerando que tanto a EC quanto o passivo ambiental são temas ainda complexos de análise, sugere-se para pesquisas futuras, a análise da EC e do passivo ambiental de empresas de outros segmentos.

\section{REFERÊNCIAS}

ABADIA, L. G.; GALVÃO, G. D. A.; CARVALHO, M. M. Economia Circular: Um Estudo Bibliométrico. In: ENCONTRO NACIONAL DE ENGENHARIA DE PRODUÇÃO, 36. Anais. São Paulo, 2016.

ABIT. Associação Brasileira da Indústria Têxtil e de Confecção. O Poder Da Moda: Cenários, Desafios, Perspectivas. Agenda de Competitividade da Indústria Têxtil e De Confecção Brasileira 2015-2018.2019.

ABREU, M. C. S.; CASTRO, F. C.; LAZARO, J. C.. Avaliação da influência dos stakeholders na pró-atividade ambiental de empresas brasileiras. Revista de Contabilidade e Organizações, São Paulo, v.7, n.17, p.20-32, 2013.

AMARAL, M. C.; ZONATTI, W. F.; SILVA, K. L.; KARAM JUNIOR, D.; AMATO NETO, J.; BARUQUE-RAMOS, J.. Industrial textile recycling and reuse in Brazil: case study and considerations concerning the circular economy. Gestão \& Produção, v.25, n.3, p.431-443, 2018.

BARDIN, L.. Análise de conteúdo. Lisboa: 70, 1995.

BERLIN, L. G.. Indústria Têxtil Brasileira e suas adequações na implementação do Desenvolvimento Sustentável. Moda Palavra E-Periódico, v.13, p.15-45, 2014.

BOSZCZOWSKI, A. K.; TEIXEIRA, R. M.. O Empreendedorismo Sustentável e o processo empreendedor: em busca de oportunidades de novos negócios como solução para problemas sociais e ambientais. Revista Economia \& Gestão, v.12, n.29, p.141-168, 2012

BRASIL. Lei n. 10.650, de 16 de abril de 2003. Dispõe sobre o acesso público aos dados e informações existentes nos órgãos e entidades integrantes do Sisnama. Brasília: DOU, 2003.

BURGWAL, D. V.; VIEIRA, R. J. O.. Determinantes da divulgação ambiental em companhias abertas holandesas. Revista Contabilidade \& Finanças, v.25, n.64, p.60-78, 2014.

C\&A. Relatório Global de Sustentabilidade 2018. Barueri: 2019.
CEGLIA, D.. Uma análise complexa e rizomática da indústria da moda: em Direção a uma economia criativa circular. Tese (Doutorado em Administração) - Universidade Federal do Rio Grande do Sul, Porto Alegre, 2020.

CLARO, P.; CLARO, D. P. E.; AMANCIO, R.. Entendendo o conceito de sustentabilidade nas organizações. Revista de Administração, v.43, n.4, 2008.

DEMAJOROVIC, J.; MIGLIANO, J.. Política Nacional de Resíduos Sólidos e suas implicações na cadeia da logística reversa de microcomputadores no Brasil. Gestão \& Regionalidade, v.29, n.87, 2013.

ECYCLE. Guia da compostagem: recicle todo resíduo orgânico da sua casa de maneira sustentável. 2008.

EMF. Ellen Macarthur Foundation. What Is The Circular Economy?. 2017.

FERREIRA, A. C. S.. Contabilidade ambiental: uma informação para o desenvolvimento sustentável. São Paulo: Atlas, 2011.

FRY, L. W.; SLOCUM JUNIOR, J. W.. Maximizing the triple bottom line through spiritual leadership. Organizational Dynamics, v.37, n.1, p.86-96, 2008.

GIL, A. C.. Métodos e técnicas de pesquisa social. São Paulo: Atlas, 1999.

GRUPO SOMA. Responsabilidade ambiental. Rio de Janeiro: 2019.

HABERMAS, J.. Consciência moral e agir comunicativo. Rio de Janeiro: Tempo Brasileiro, 1989.

IBGE. Instituto Brasileiro de Geografia e Estatística. Pesquisa Nacional de Saneamento Básico 2008. Rio De Janeiro: IBGE, 2010.

KIM, H. J.. A Study of high value-added upcycled handbag designs for the Dubai Luxury Fashion Market. Journal of the 
Korean Society of Fashion Design, v.14, p.173-188, 2014.

LAGO, A. A. C.. Estocolmo, Rio, Joanesburgo: O Brasil e as três conferências ambientais das Nações Unidas. Brasília: Fundação Alexandre Gusmão, 2007.

LIPOVETSKY, G.. O Império do Efêmero: A Moda e seu destino nas sociedades modernas. São Paulo: Companhia das Letras, 2009.

LOJAS RENNER. Responsabilidade Ambiental, 2019. 2020

LOJAS RENNER. Balanço Anual 2019. 2020.

LOJAS RENNER. Balanço Anual 2018. 2019.

LUCIETTI, T. J.; TRIERWEILLER, A. C.; RAMOS, M.S.; SORATTO, R. B.; MACIEL, C. E.; VEFAGO, Y.. O Upcycling Como Alternativa Para Uma Moda Sustentável. Revista Internacional Interdisciplinar Interthesis, v.15, n.2, p.143159, 2019.

LÜDEKE-FREUND, K.; GOLD, S.; BOCKEN, N. M. P.. A Review and Typology of Circular Economy Business Model Patterns. Journal of Industrial Ecology, v.23, n.1, p.36-61, 2018.

LÜDKE, M.; ANDRÉ, M. E. D. A.. Pesquisa em educação: abordagens Qualitativas. São Paulo: Epu, 1986.

MARQUES, L. O.; ARRUDA, L. L.; GARBRECHT, G. T.; MATTOS, M. A.. Passivo Ambiental: Uma Reflexão Para A Contabilidade. In: CONGRESSO BRASILEIRO DE CUSTOS, 23. Anais. Porto de Galinhas, 2016.

MEADOWS, D. H.; MEADOWS, D. L.; RANDERS, J.; BEHRENS III, W.. Limites do Crescimento: Um relatório para o projeto do Clube de Roma sobre o dilema da humanidade. São Paulo: Perspectiva, 1972.

MOREIRA, R. N.; MARINHO, L. F. L.; BARBOSA, F. L. S.; BIZARRIA, F. P. A.. O Modelo de Produção Sustentável Upcycling: O Caso da Empresa Terracycle. Revista Ambiência, v.14, n.1, p.72-84, 2018.

MORO, R. C. L.; PAULINO, S. R.; CASTRO, P. H.. Iniciativas da Cadeia de Suprimentos Têxtil para implementação da Cnd/Brasil. In: SEMEAD, SEMINÁRIOS DE ADMINISTRAÇÃO, 21. Anais. São Paulo, 2018.

ONU BR. Nações Unidas no Brasil. A Agenda 2030. ONU BR, 2015.

NOBRE, F. S.; RIBEIRO, R. E. M.. Cognição e Sustentabilidade: Estudo de casos múltiplos no índice de sustentabilidade empresarial da BM\&FBOVESPA. Revista de Administração Contemporânea, v.17, n.4, p.499-517, 2013.

OLIVEIRA, G. B.. Uma discussão sobre o conceito de desenvolvimento. Revista da FAE, v.5, n.2, p.41-48, 2002.

PEARCE, D. W.; TURNER, K.. Economics of natural resources and the environment. Baltimore: John Hopkins University Press, 1990.
PEREIRA, N. C.. Rematerial-oriented design: a framework for architectural upcycling. Tese (Doctor of Philosophy) - Curtin University, Bentley, 2017.

PINTO, A.; SOUSA, C.. Roupas feitas de roupas. Revista de Iniciação Científica, Tecnológica e Artística, v.5, n.3, p.4767, 2015.

RIBEIRO, M. S.. Contabilidade Ambiental. São Paulo: Saraiva, 2010 .

RICHARDSON, M.. Design for reuse: integrating upcycling into industrial design practice. In: INTERNATIONAL CONFERENCE ON REMANUFACTURING. Anais. University Of Strathclyde, Glasgow, 2011.

SANTOS, B. A.; RIOS, R. P.. Nível de divulgação ambiental: verificação em um grupo de Empresas Brasileiras. Revista Eletrônica Gestão e Negócios, v.1, p.1-20, 2017.

SANTOS, A. O.; SILVA, F. B.; SOUZA, S.; SOUSA, M. F. R. Contabilidade Ambiental: um estudo sobre sua aplicabilidade em empresas brasileiras. Revista Contabilidade \& Finanças, v.16, n.27, p.89-99, 2001.

SHOUP, K.. Rubbish! Reuse Your Refuse. New Jersey: Wiley Publishing, 2008.

SOUZA, N. E.; EMÍDIO, F. B.. Diferenciação e Sustentabilidade a partir do redesign de roupas de brechó: um modelo de estratégia produtiva. Moda Palavra E-Periódico, v.9, p.2341,2015

SU, B.; HESHMATI, A.; GENG, Y.; YU, X.. A review of the circular economy in china: moving from rethoric to implementation. Journal Cleaner Production, v.42, p.215$277,2013$.

TENÓRIO, F. G.. 'O Mito Da Participação'. Revista De Administração Pública, v.24, n.3, p.162-164, 1990.

VELLANI, C. L.; RIBEIRO, M. S.. Sistema contábil para gestão da ecoeficiência empresarial. Revista Contabilidade \& Finanças, v.20, n.49, p.25-43, 2009.

VOGT, M.; DEGENHART, L.; ROSA, F. S.; HEIN, N.. Responsabilidade Social e Ambiental: análise dos impactos ambientais de transporte dos relatórios anuais e de sustentabilidade das Empresas Brasileiras. Revista em Agronegócio e Meio Ambiente, v.9, n.4, p.889-915, 2016.

WEBER, M.. Ensaios de sociologia. Rio de Janeiro: LTC, 1982

ZONATTI, W. F.. Geração de resíduos sólidos da indústria brasileira têxtil e de confecção: materiais e processos para reuso e reciclagem. Tese (Doutorado em Ciências), Universidade de São Paulo, São Paulo, 2016.

ZUCCHELLA, A.; PREVITALI, P.. Circular business models for sustainable development: a 'waste is food' restorative ecosystem. Business Strategy and the Environment, v.28, p.274-285, 2018.

A CBPC - Companhia Brasileira de Produção Científica (CNPJ: 11.221.422/0001-03) detém os direitos materiais desta publicação. Os direitos referem-se à publicação do trabalho em qualquer parte do mundo, incluindo os direitos às renovações, expansões e disseminações da contribuição, bem como outros direitos subsidiários. Todos os trabalhos publicados eletronicamente poderão posteriormente ser publicados em coletâneas impressas sob coordenação da Sustenere Publishing, da Companhia Brasileira de Produção Científica e seus parceiros autorizados. Os (as) autores (as) preservam os direitos autorais, mas não têm permissão para a publicação da contribuição em outro meio, impresso ou digital, em português ou em tradução. 